\title{
TOKSISITAS AKUT DEKOK DAUN KERSEN (Muntingia calabura) MENGGUNAKAN METODE BSLT (Brine Shrimp Lethality Test)
}

\author{
Rosa Fatimah"), Bilal Subchan Agus Santoso ${ }^{1 *)}$ \\ 1) Akademi Farmasi Putra Indonesia Malang \\ Korespondensi : bilalsas67@gmail.com
}

\begin{abstract}
Kersen (Muntingia calabura) leaf is a kersen plant parts are usually processed by the community into traditional medicine in the form of a drink by boiling. The boiling process that is too long allows the secondary metabolite compounds contained in kersen leaf to be damaged or reduced, therefore it is necessary to do a screening test of secondary metabolites of decoction of kersen leaf, besides plants containing secondary metabolites can be toxic, so that testing needs to be done components of chemical compounds that have toxic activity. The aims of this study was to know the minimum concentration of acute toxic and component of decoction of kersen leaf. Toxicity testing was carried out using the BSLT method (Brine shrimp lethality test) with test animals using Artemia salina Leach larvae in each treatment with various concentrations of $250 \mathrm{mg} \mathrm{L}-1$, $\mathrm{mg} \mathrm{L}-1,500 \mathrm{mg} \mathrm{L}-1,1000 \mathrm{mg} \mathrm{L}-1,1500 \mathrm{mg} \mathrm{L}-1$, $2000 \mathrm{mg} \mathrm{L}-1,25000 \mathrm{mg} \mathrm{L}-1$ and replication 3 times. The results of screening secondary metabolites were flavonoides, tannins, and alkaloids. The results of the acute toxicity test showed the LC50 value was $621.25 \mathrm{mg}$ L-1.
\end{abstract}

Key word: Kersen Leaf, decoction, toxicity, BSLT

\begin{abstract}
ABSTRAK
Daun kersen (Muntingia calabura) merupakan bagian tanaman kersen yang biasanya diolah oleh masyarakat menjadi obat tradisional dalam bentuk minuman dengan cara direbus. Proses perebusan yang terlalu lama memungkinkan senyawa metabolit sekunder yang terdapat pada daun kersen menjadi rusak atau berkurang maka dari itu perlu dilakukan uji skrining senyawa metabolit sekunder pada daun rebusan daun kersen selain itu tanaman yang mengandung senyawa metabolit sekunder dapat bersifat toksik, sehingga perlu dilakukan pengujian mengenai komponen senyawa kimia yang memiliki aktivitas toksik. Tujuan penelitian ini untuk mengetahui konsentrasi minimum dari rebusan daun kersen yang bersifat toksik. Pengujian toksisitas dilakukan menggunakan metode BSLT dengan hewan uji menggunakan larva Artemia salina Leach pada masing-masing perlakuan dengan variasi konsentrasi yaitu $250 \mathrm{mg} \mathrm{L}-1, \mathrm{mg} \mathrm{L}-1,500 \mathrm{mg} \mathrm{L}-1$,

$1000 \mathrm{mg} \mathrm{L}-1,1500 \mathrm{mg}$ L-1, $2000 \mathrm{mg} \mathrm{L}-1,25000 \mathrm{mg}$ L-1 dan dilakukan replikasi sebanyak 3 kali. Dari hasil skrining metabolit sekunder diketahui bhawa rebusan daun kersen memilki senyawa metabolit sekunder flavonid, tanin, dan alkaloid. Hasil uji toksisitas menunjukkan bahwa rebusan daun kersen dapat memberikan efek toksik akut pada hewan uji dengan nilai LC50 sebesar 621,25 mg L-1.
\end{abstract}

Kata Kunci: Daun kersen, Rebusan, toksisitas, BSLT 


\section{PENDAHULUAN}

Indonesia merupakan negara yang kaya akan keanekaragaman tumbuh- tumbuhan. Tumbuhan sebagai bahan alami biasanya digunakan sebagai bahan obat karena umumnya memiliki senyawa metabolit sekunder. Metabolit sekunder merupakan senyawa yang dihasilkan oleh tumbuhan yang memiliki aktifitas farmakologi. Senyawa metabolit sekunder yang terdapat pada tumbuhan biasanya flavonoid, tanin, alkaloid, triterpenoid, steroid, dan tanin. Beberapa senyawa metabolit memiliki kemampuan sebagai antioksidan, antibakteri, dan antinflamasi (Tulung et al., 2017)

Salah satu tumbuhan yang sering dimanfaatkan oleh masyarakat Indonesia sebagai obat tradisional yaitu daun kersen (Muntingia calabura). Kersen berasal dari America tropis sehingga sangat mudah dijumpai di daerah tropis seperti Indonesia. Tanaman ini biasanya tumbuh di halaman rumah atau dipinggir jalan. Umumnya tanaman kersen dimanfaatkan sebagai peneduh selain itu bagian buah dan daun dari tanaman ini banyak dimanfaatkan oleh masyarakat sebagai obat tradisional. Daun kersen sendiri biasanya diolah oleh masyarakat menjadi obat tradisional dalam bentuk minuman dengan cara direbus. Penelitian mengenai senyawa yang terkandung dalam tumbuhan kersen sudah banyak dilakukan. Pada penelitian yang dilakukan oleh (Nurhasanah, 2016) diketahui bahwa daun kersen memiliki kandungan senyawa metabiolit sekunder alkaloid, flavonoid, polifenol, steroid- triterpenoid, tanin, monoterpena- seskuiterpena serta saponin. Sedangkan menurut penelitian yang dilakukan oleh (Sentat and Pangestu, 2016) diketahui bahwa ekstrak etanol daun kersen mengandung senyawa metabolit sekunder seperti flavonoid, tanin dan saponin. Selain itu dari hasil peneitian yang dilakukan oleh (Widiastuti et al., 2017) diketahui bahwa infusa daun kersen mengandung senyawa kimia flavonoid, saponin, dan tanin. Tanaman yang mengandung senyawa metabolit sekunder dapat bersifat toksik, sehingga perlu dilakukan pengujian mengenai komponen senyawa kimia yang memiliki aktivitas toksik. Uji toksisitas perlu dilakukan untuk menetahui konsentrasi minimum dari suatu tanaman agar bersifat toksik (Tulung et al., 2017).

Uji toksititas dapat dilakukan menggunakan metode BSLT (Brine Shrimp Lethality Test). Uji toksisitas menggunakan metode BSLT bertujuan untuk mengetahui kadar kandungan senyawa yang berpotensi sebagai racun pada pertumbuhan sel. BSLT merupakan salah satu metode pengujian toksisitas menggunakan larva udang Artemia salina Leach sebagai hewan uji. Prinsip metode pengujian menggunakan BSLT berdasarkan senyawa aktif dan sifat toksiknya yang dapat membunuh larva udang Artemia salina Leach sebagai hewan uji (Sukandar et al., 2007). Metode ini dilakukan untuk melihat tingkat mortalitas larva udang Artemia salina Leach yang disebabkan oleh bahan uji. Hasil yang diperoleh dihitung sebagai LC50 (letal concentration) bahan uji, yaitu jumlah dosis atau konsentrasi bahan uji yang dapat menyebabkan kematian larva udang sejumlah $50 \%$ setelah masa inkubasi 24 jam (Lisdawati et al., 2006).

Berdasarkan pengalaman empiris, daun kersen biasanya dijadikan sebagai obat tradisonal dalam bentuk minuman dengan cara di rebus. Maka dari itu peneliti akan melakukan uji toksisitas rebusan daun kersen untuk mengetahui konsentrasi minimun toksik yang terdapat dalam rebusan daun kersen.

\section{METODE PENELITIAN}

Alat dan bahan yang digunakan dalam penelitian ini diantaranya yaitu tabung reaksi, panci alumunium, aera- 
tor, lampu neon, labu ukur, batang, beker gelas, gelas ukur, daun kersen, air, aquades, air laut, larva udang (Artemia salina Leach), $\mathrm{FeCl} 3$, serbuk magnesium, dan asam klorida $2 \mathrm{~N}$, reagen mayer, dragendof, wagner.

\section{Rancangan Penelitian}

Metode peneltian yang digunakan pada penelitian ini yaitu metode penelitian eksperimental dengan post test only control group design menggunakan uji BSLT untuk mengetahui toksisitas infusa daun kersen (Muntingia calabura) terhadap larva udang Artemia salina Leach dengan beberapa konsentrasi infusa yang digunakan. Penelitian ini dilakukan dengan beberapa tahapan yaitu determinasi tumbuhan, pengumpulan bahan, pembuatan rebusan daun kersen, skrining fitokimia, penyiapan bahan uji, dan penetasan larva udang, pelaksanaan uji dengan metode BSLT, dan analisa data.

\section{Pengambilan bahan}

Bagian tumbuhan kersen yang digunakan pada penelitian ini yaitu bagian daun. Daun kersen dipetik dan ditimbang setelah itu dicatat hasil penimbangan daun kersen yang sudah dipetik dari pohonnya.

\section{Determinasi Tumbuhan}

Determinasi bagian tanaman kersen dilakukan dengan bantuan Lembaga Balai Materia Medika Batu.

\section{Pembuatan bahan uji (Rebusan Daun} Kersen)

Bahan uji dibuat dengan cara merebus daun kersen sebanyak $400 \mathrm{~g}$ kedalam $800 \mathrm{ml}$ air dengan api sedang hingga menjadi setengah volume awal.

\section{Skrining fitikimia}

Skrinig fitokimia yang dilakukan bertujuan untuk mengetahui adanya senyawa metabolit sekunder tani, saponin, dan flavonoid yang terdapat pada rebusan daun kersen dengan metode pereaksi menggunakan uji warna dan pengendapan.

\section{Penetasan telur larva}

Penetasan telur larva dilakukan dengan diambil telur Artemia salina Leach sebanyak 1,5 gram dan direndam telur tersebut dalam air laut buatan 20\% sebanyak 2 liter dan diterangi dengan lampu serta diaerasi dengan aerator selama 48 jam (Juniartini, 2009).

\section{Pembuatan larutan induk}

Larutan induk diambil dari hasil rebusan daun kersen dengan konsentrasi $10 \% \mathrm{~b} / \mathrm{v}$.

\section{Pembuatan larutan baku kerja}

Pembuatan larutan kerja diambil masing-masing dari larutan induk diambil hingga menjadi beberapa konsentrasi yaitu $250 \mathrm{mg} \mathrm{L}-1,500 \mathrm{mg} \mathrm{L}-1$, $1000 \mathrm{mg} \mathrm{L}-1,1500 \mathrm{mg} \mathrm{L}-1,2000 \mathrm{mg}$ L1.

\section{Pelaksanaan uji BSLT}

Disiapkan 5 tabung reaksi, lalu isi tabung reaksi dengan larutan baku kerja dengan masing-masing konsentrasi yaitu $250 \mathrm{mg} \mathrm{L}-1,500 \mathrm{mg} \mathrm{L}-1,1000$ mg L-1, 1500 mg L-1, 2000 mg L-1. Tabung reaksi diisi sebanyak air rebusan daun kersen dan air laut denga pebandingan 1:1 yaitu $5 \mathrm{ml}$ rebusan daun kersen dan $5 \mathrm{ml}$ hingga menjadi konsentrasi $250 \mathrm{mg} \mathrm{L}-1,500 \mathrm{mg} \mathrm{L}-1$, $1000 \mathrm{mg} \mathrm{L}-1,1500 \mathrm{mg} \mathrm{L}-1$, dan 2000 mg L-1. setelah itu dimasukkan larva Artemia salina Leach sebanyak 10 ekor pada masing-masing vial. Masingmasing vial selajutnya diinkubasi dalam suhu kamar selama 24 jam dibawah penerangan lampu. Perhitungan dilakukan dengan melihat larva Artemia salina Leach yang mati disetiap jam ke24 dari setiap konsentrasi. Cara menghitung larva udang yang mati yaitu dilakukan dengan cara manual dengan bantuan pengelihatan mata di bawah penyinaran lampu agar larva Artemia salina Leach yang mati dapat terlihat dengan jelas. Uji BSLT dilakukan replikasi sebanyak 3 kali pada masingmasing kelompok perlakuan. 
HASIL DAN PEMBAHASAN

Tabel 1. Organoleptis Air Rebusan

Daun Kersen

Organoleptik Dekok daun kersen

\begin{tabular}{ll} 
Bentuk & Cair \\
\hline Warna & Coklat kekuningan \\
\hline Bau & Khas
\end{tabular}

Tabel 2. Hasil Analisis Senyawa Metabolit Sekunder

\begin{tabular}{ll}
\hline Kandungan kimia & Hasil \\
\hline Flavonoid & + \\
\hline Tanin & + \\
\hline Saponin & - \\
\hline Alkaloid & + (Mayer, Dragendorf) \\
\hline
\end{tabular}

Tabel 3. Hasil pengamatan kematian larva udang

\begin{tabular}{lllllll}
\hline Replikasi ke & \multicolumn{6}{c}{ Angka kematian larva } \\
\cline { 2 - 7 } & \multicolumn{6}{c}{ Konsentrasi dekok } \\
\cline { 2 - 7 } & 250 & 500 & 1000 & 1500 & 2000 & $\mathrm{~K}(-)$ \\
\hline $\mathbf{1}$ & 3 & 4 & 5 & 9 & 9 & 0 \\
\hline $\mathbf{2}$ & 2 & 3 & 5 & 8 & 10 & 0 \\
\hline Total kematian & 0 & 5 & 7 & 7 & 10 & 0 \\
\hline Rata-rata & 0,1667 & 0,4 & 0,56 & 0,8 & 0,96 & 0 \\
\hline \% kematian & 16,7 & 40 & 56 & 80 & 96 & 0 \\
\hline
\end{tabular}

Tabel 4. Data pengamatan kematian larva udang menggunakan analisa probit

\begin{tabular}{|l|l|l|l|l|l|}
\hline $\begin{array}{l}\text { Konsentrasi } \\
\left(\mathrm{mg} \mathrm{L}^{-1}\right)\end{array}$ & Log mg L & Probit & $\begin{array}{l}\% \\
\text { kematian }\end{array}$ & Kematian & Total \\
\hline 250 & 2,398 & 4,05 & 17 & 5 & 30 \\
\hline 500 & 2,699 & 4,75 & 40 & 12 & 30 \\
\hline 1000 & 3,000 & 5,18 & 57 & 17 & 30 \\
\hline 1500 & 3,176 & 5,84 & 80 & 24 & 30 \\
\hline 2000 & 3,301 & 6,88 & 97 & 29 & 30 \\
\hline
\end{tabular}

Grafik 1. Data pengamatan kematian larva udang menggunakan analisa probit

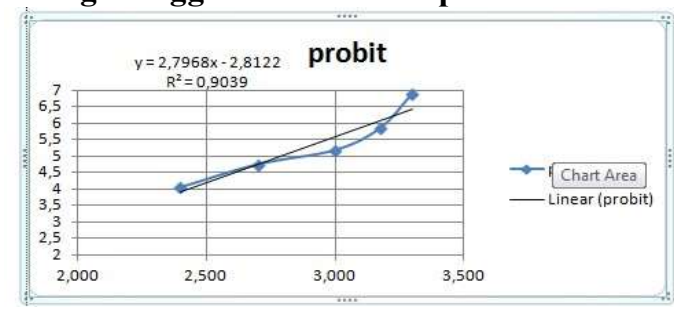

$$
\begin{array}{ll}
\text { Persamaan } & : y=a x+b \\
& : y=2,7968 x-2,8122 \\
& : 5=2,7968 \mathrm{x}-2,8122 \\
& : \mathrm{x}= \\
& 2,7933 \\
& =\operatorname{antilog}(\mathrm{x}) \\
& =\operatorname{antilog}(2,7933) \\
& =621,25 \mathrm{mg} \\
\text { LC }_{50} & \mathrm{~L}^{-1}
\end{array}
$$

Dari data yang peroleh yaitu berupa perhitungan $\mathrm{LC}_{50}$ dengan menggunakan microsoft office excel didapatkan persamaan garis lurus $\mathrm{y}=$ 2,7968x - 2,8122, lalu diamsukkan angka 5 pada nilai $\mathrm{Y}$ sehingga didapatkan nilai $\mathrm{LC}_{50} 621,25 \mathrm{mg} \mathrm{\textrm {L } ^ { - 1 }}$. $\mathrm{LC}_{50}$ termasuk dalam kategori toksik jika nilainya kurang dari $1000 \mathrm{mg} \mathrm{L}^{-1}$, menurut (Sadli et al., 2015) nilai $\mathrm{LC}_{50}$ sesuai dengan tingkat konsentrasinya, yaitu kategori sangat tinggi (highly toxic) dengan konsentrasi $1-10 \mathrm{mg} \mathrm{L}^{-}$ ${ }^{1}$, sedangkan kategori sedang (medium toxic) pada konsentrasi $10-100 \mathrm{mg} \mathrm{L}^{-1}$, dan kategori rendah (low toxic) pada konsentrasi 100-1000 $\mathrm{mg} \mathrm{L}^{-1}$. Pada penelitian ini nilai $\mathrm{LC}_{50}$ sebesar $621,25 \mathrm{mg} \mathrm{\textrm {L } ^ { - 1 }}$. Sedangkan dari penelitian (Setyowati, 2016) disebutkan bahwa $\mathrm{LC}_{50}$ dari ekstrak daun kersen yang menggunakan pelarut etanol sebesar 295,763 $\mathrm{mg} \mathrm{L}^{-1}$. Hasil penelitian tersebut sangat berbeda dengan hasil yang didapatkan pada penelitian ini. hal ini dikarenakan metode ekstrasi yang berbeda serta pemanasan yang cukup lama pada penelitian ini sehingga kandungan kimia pada daun kersen kemungkinan banyak berkurang.

Aktivitas toksik yang ada pada ekstrak daun kersen timbul karena kandungan senyawa metabolit sekunder yang dimiliki tanaman tersebut. Diantara beberapa senyawa metabolit sekunder yang dimiliki daun kersen, flavonoid diperkirakan memiliki peran terbesar dimana pada kadar tertentu, flavonoid mempunyai tingkat toksisitas akut (Setyowati, 2016). Mekanisme flavonoid yang berkaitan adalah sebagai sebagai antioksidan.

Selain flavonoid, metabolit sekunder yang lain juga berperan terhadap timbulnya aktivitas toksik dari ekstrak daun kersen yaitu dengan bertindak sebagai racun perut. Apabila 
senyawa-senyawa tersebut masuk ke dalam tubuh larva, alat pencernaannya akan terganggu dan dapat menyebabkan kematian (Setyowati, 2016). Berdasarkan nilai $\mathrm{LC}_{50}$ sebesar $621,25 \mathrm{mg}$ $\mathrm{L}^{-1}$, maka dapat dikatakan bahwa ekstrak daun kersen memiliki aktivitas toksik dan berpotensi untuk dikembangkan lebih lanjut pada penelitian yang berhubungan dengan toksisitas.

\section{KESIMPULAN}

1. Uji BSLT air rebusan (dekok) daun kersen memiliki aktivitas sitotoksik terhadap larva artemia salina dengan nilai $\mathrm{LC}_{50}$ sebesar $621,25 \mathrm{mg} \mathrm{L}^{-1}$ sehingga masuk dalam kategori toksik karena memiliki $\mathrm{LC}_{50}<1000 \mathrm{mg} \mathrm{L}^{-1}$.

2. Air rebusan daun kersen mempunyai kandungan senyawa alkaloid, flavonoid, dan tanin.

\section{DAFTAR PUSTAKA}

Arwan, B., 2017. Fakultas Kedokteran dan Ilmu Kesehatan Universitas Islam Negeri Alauddin Makassar Samata- Gowa 98.

BPOM RI, 2014. Pedoman Uji Toksisitas Nonklinik Secara In Vivo. BPOM RI, Jakarta.

Kosasih, E., Ana, E., Encun, 2013. Informasi singkat benih kersen/talok (Muntingia calabura L.). Balai pembenihan Tanaman Hutan Jawa dan Madura.

Kristanti, A.N., Aminah, N.S., Tanjung, M., Kurniadi, B., 2008. Buku Ajar Fitokimia. Jurusa Kimia Laboratorium Kimia Organik, Surabaya.

Kuntorini, E.M., 2013. Struktur Anatomi dan Uji Aktivitas Antioksidan Ekstrak Metanol Daun Kersen 6.

Lenny, S., 2006. Senyawa Flavonoida, Fenilpropanoida dan Alkaloida 25.

Lestari, J.H.S., 2016. Dekok Daun Kersen (Muntingia Calabura) Sebagai Cairan Sanitasi Tangan dan Buah Apel Manalagi (Malus Sylvestris).
Malangngi, L.P., Sangi, M.S., Paendong, J.J.E., Kimia, J., 2012. Penentuan Kandungan Tanin dan Uji Aktivitas Antioksidan Ekstrak Biji Buah Alpukat (Persea americana Mill.) 6.

Millati, N., 2016. Uji Toksisitas dengan Metode BSLT Senyawa Steroid Fraksi Petroleum Eter Mikroalga chlorella sp. Universitas Islam Negeri Maulana Malik Ibrahim Malang.

Mujiman, A., 2001. Makanan ikan. Penebar swadaya, Jakarta.

Nurhasanah, N., 2016. Isolation of Antioxidant Compound of Muntinga Calabura Linn Leave. https://doi.org/10.13140/rg.2.1.11 12.1687

Purnamaningsih, H., Nururrozi, A., Indarjulianto, S., 2017. Saponin: Dampak terhadap Ternak (Ulasan) 6,12.

Redha, A., 2010. Flavonoid: Struktur, Sifat Antioksidatif Dan Peranannya Dalam Sistem Biologis 7.

Reskianingsih, A., 2014. Uji Toksisitas Akut Ekstrak Metanol Buah Phaleria macrocarpa (Scheff) Boerl Terhadap Larva Artemia Leach Dengan Metode Brine Shrimp Lethality Test (BSLT). Universitas Islam Negeri, Jakarta.

Sadli, Utami, N. wahyu, Sari, I., 2015. The Cytotoxic Activity Of Ethylacetatefraction of Kersen (Muntingia Calabura) Leaves Against Larvae Shrimp Artemia Salina Leach.

Sari, C.I.P., 2012. Kualitas minuman serbuk Kersen (Muntingia calabura L.) dengan variasi konsentrasi maltodekstrin dan ekstrak kayu secang (Caesalpinia sappan L.). Skripsi, Fakultas Teknobiologi, Universitas Atma Jaya, Yogyakarta. 
Sari, W.P., 2010. Program Studi Farmasi Fakultas Kedokteran dan Ilmu Kesehatan Universitas Islam Negeri Syarif Hidayatullah Jakarta 145. Sentat, T., Pangestu, S., 2016. (Muntingia calabura L.) Pada Mencit Putih Jantan (Mus musculus) Dengan Induksi Nyeri Asam Asetat7.

Setyowati, W.A.E., 2016. Kandungan Kimia Dan Uji Aktivitas Toksik Menggunakan Metode Bslt (Brine Shrimp Lethality Test) 7.

Sukandar, D., Hermanto, S., Lestari, E.,2007. Uji Toksisitas Ekstrak Daun Pandan Wangi (Pandanus maryllifolius Roxb.) Dengan Metode Brine Shrimp Lethality Test (BSLT)8.

Tulung, P.C., Rorong, J.A., Pontoh, J., 2017. KERSEN (Muntingia calabura) 10,5 .

Widiastuti, R., Sary, R.R., Aini, R., 2017.Aktivitas Antelmintika Infusa Daun Kersen (Muntingia calabura Linn) Terhadap Cacing Ascaridia galli Schrank Secara In Vitro 4.

Zahara, M., 2018. Kajian Morfologi dan Review Fitokimia Tumbuhan Kersen (Muntingia calabura L) 5,7 . 